\title{
Rollover of Liquid Natural Gas in a Storage Tank: A Numerical Simulation
}

\author{
Yinbin $\mathrm{LU}^{1}$ and Chenwei LIANG \\ School of Mechanical Engineering, Xi'an Shiyou University, Xi'an, China
}

\begin{abstract}
In the filling and transportation processes of liquefied natural gas (LNG), the safety of LNG storage tanks is compromised because of rollover phenomenon. As such, the rollover factors of $L N G$ in a storage tank should be identified to prevent or weaken the rollover intensity of LNG. In this study, the rollover behavior of LNG in a storage tank is numerically simulated. The density of the two layers in a LNG storage tank is related to temperature in our numerical model. It is found that the greater the significant initial density difference (range of $1-12 \mathrm{~kg} \cdot \mathrm{m}^{-3}$ ) is, the more obvious the LNG rollover will be. A density difference of $7.5 \mathrm{~kg} \cdot \mathrm{m}^{-3}$ is found as the critical density difference in the present work. When the initial density difference exceeds the critical density difference, the LNG rollover coefficients increase dramatically. Moreover, an LNG rollover model with two daughter models is proposed, which are divided by the critical initial density difference, i.e., a cubic relationship between rollover coefficients and the initial density difference when the density difference is less than $7.5 \mathrm{~kg} \cdot \mathrm{m}^{-3}$ and secondly, a linear relationship between the rollover coefficient and the double exponential functions when the density difference is larger than $7.5 \mathrm{~kg} \cdot \mathrm{m}^{-3}$.
\end{abstract}

Keywords. LNG, rollover, density, critical density difference

\section{Introduction}

Liquid natural gas (LNG) is usually stored and transported in a liquid form at nearly atmospheric pressures and at temperatures close to $-162^{\circ} \mathrm{C}$. When $\mathrm{LNG}$ is injected into storage tanks and mixed with the residual LNG, LNG stratification appears. Soon after, rollover occurs because of stratified liquids in storage systems [1-3]. Two well-known rollover accidents occurred in the Snam LNG Distribution Station and the Partington LNG Pitch Peak Station in 1971 and 1993, respectively [4, 5] Considering the two serious events, many researchers studied the mechanism of LNG rollover and suppression measures although previous related studies were conducted even before the two incidents happened [6-10]. In 1972, Chatterjee and Geist [7] first proposed a rollover model, i.e., the C-G model. Then, Heestand [9] developed the C-G model and obtained the HSM model. In 1993, Shi et al. found a migrating interface from experiments [11]. Thereafter, a rollover model that first considered the liquid interface as a dynamic state was established [12-15].

Previous rollover investigations preferably explained the evolution from stratification formation to rollover occurrence. Few models have been proposed to describe the rollover coefficients of stratified LNG layers. Therefore, the mechanism of

1 Corresponding Author, Yinbin LU, School of Mechanical Engineering, Xi'an Shiyou University, Xi’an, China; Email: yblu@xsyu.edu.cn. 
LNG rollover should be studied to accurately predict the relationship between rollover coefficients and density and ensure the safety of LNG storage tanks.

\section{Numerical Models of LNG Rollover}

\subsection{Description of the Geometric Model of LNG Rollover}

In our geometric model of LNG rollover, LNG is injected into a storage tank that already contains a stored LNG. A 2D LNG storage tank is presented as figure 1 .

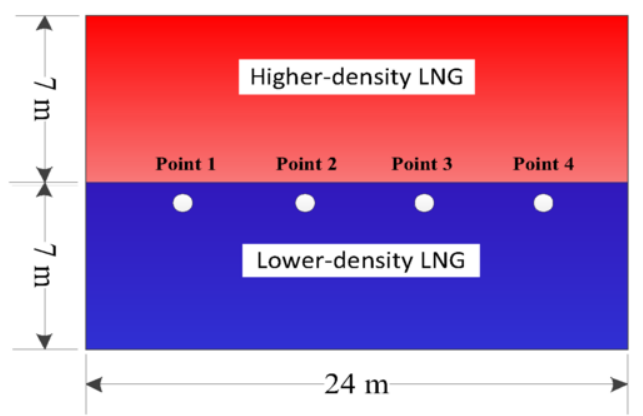

Figure 1. Geometric model of a stratified LNG.

\subsection{Mathematical Model and Governing Equations}

(1) Continuous equations

$$
\frac{\partial u_{i}}{\partial x_{i}}=0
$$

(2) Momentum equations

$$
\frac{\partial u_{i}}{\partial t}+u_{j} \frac{\partial u_{i}}{\partial x_{j}}=-\frac{1}{\rho} \frac{\partial p}{\partial x_{i}}+\left(v+v_{\mathrm{t}}\right) \nabla^{2} u_{i}+F_{i}
$$

(3) Energy equations

$$
\rho C_{\mathrm{p}}\left(\frac{\partial T}{\partial t}+u_{i} \frac{\partial T}{\partial x_{i}}\right)=\lambda \frac{\partial^{2} T}{\partial x_{i}^{2}}
$$

(4) Composition equations

$$
\rho \frac{\partial S}{\partial t}+\rho u_{j} \frac{\partial S}{\partial x_{i}}=\rho D_{\mathrm{AB}} \frac{\partial^{2} S}{\partial x_{i}^{2}}
$$

(5) Density equations 


$$
\rho \approx \rho_{0}\left[1-\beta\left(T-T_{0}\right)\right]
$$

where $\beta=0.00341$ is the thermal expansion coefficient.

The initial densities of the upper $\left(\rho_{0 \mathrm{H}}\right)$ and lower $\left(\rho_{0 \mathrm{~L}}\right)$ layers of LNG are written as follows [16]:

$$
\rho_{0 \mathrm{H}}=-1.24 T+586.49
$$

and

$$
\rho_{0 \mathrm{~L}}=-1.33 T+573.35
$$

In addition, the widely used turbulent model $k-\varepsilon$ is employed. The top of the tank is pressure outlet, and the others is wall with a constant value of $30 \mathrm{~W} \cdot \mathrm{m}^{-2}$.

\section{Results and Discussion}

\subsection{Variations in Density Contours with Time}

The density of the lower LNG layer is a constant value of $425 \mathrm{~kg} \cdot \mathrm{m}^{-3}$. The density of upper layer is larger than that of the lower layer, and the initial density difference is between 1 and $12 \mathrm{~kg} \cdot \mathrm{m}^{-3}$. The variations in density contours with time at initial density differences of 1,5 and $10 \mathrm{~kg} \cdot \mathrm{m}^{-3}$ are compared (figures 2-4).

At the beginning of the mix, the upper LNG layer seems to drop to the lower LNG layer, and the bottom layer LNG drops and moves upward at the same time. Then, the two layers mix gradually. The density of LNG tends to be identical over time because of the heat transfer between the two LNG layers, including heat leakage from the storage outside the storage tank. With careful observation, as the initial density difference widens, the mixing time shortens. For example, the density contours at 1000, 200, and $100 \mathrm{~s}$ in figures $2 \mathrm{~d}, 3 \mathrm{c}$, and $4 \mathrm{c}$ are similar.

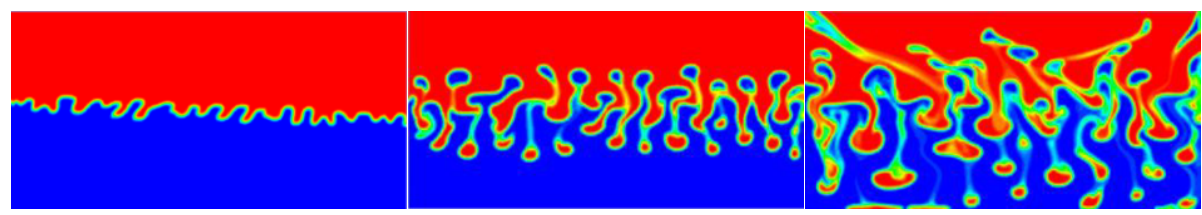

(a) $t=100 \mathrm{~s}$

(b) $t=200 \mathrm{~s}$

(c) $t=500 \mathrm{~s}$

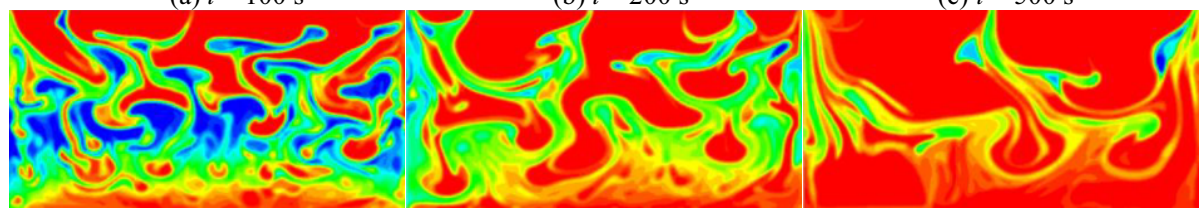

(d) $t=1000 \mathrm{~s}$

(e) $t=2000 \mathrm{~s}$

(f) $t=4000 \mathrm{~s}$

Figure 2. Variation in the density contours at an initial density difference of $1 \mathrm{~kg} \cdot \mathrm{m}^{-3}$. 


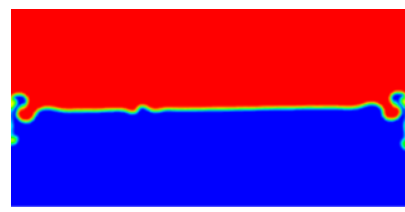

(a) $t=50 \mathrm{~s}$

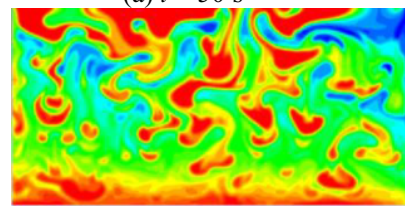

(d) $t=500 \mathrm{~s}$

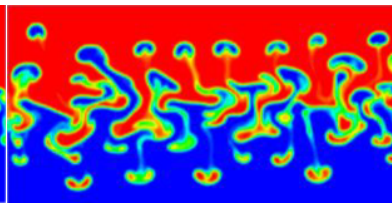

(b) $t=100 \mathrm{~s}$

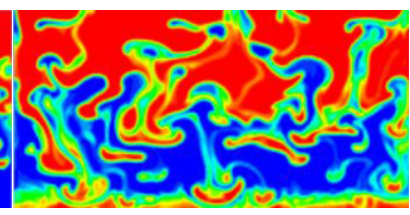

(c) $t=200 \mathrm{~s}$

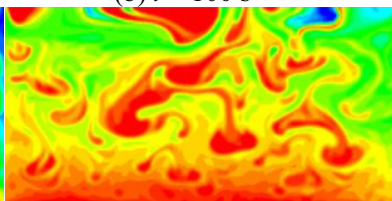

(e) $t=800 \mathrm{~s}$

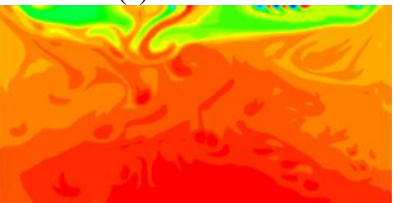

(f) $t=2000 \mathrm{~s}$

Figure 3. Variation in the density contours at an initial density difference of $5 \mathrm{~kg} \cdot \mathrm{m}^{-3}$.

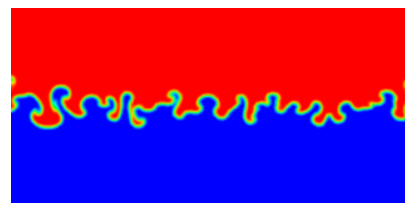

(a) $t=20 \mathrm{~s}$

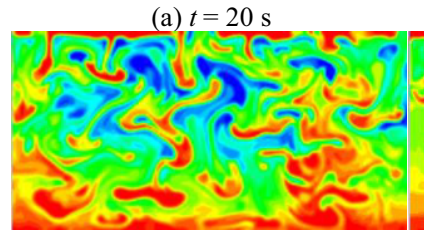

(d) $t=150 \mathrm{~s}$

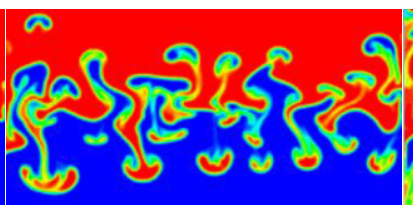

(b) $t=50 \mathrm{~s}$

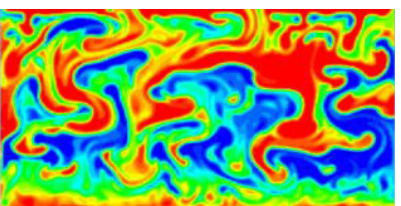

(c) $t=100 \mathrm{~s}$

Figure 4. Variation in the density contours at an initial density difference of $10 \mathrm{~kg} \cdot \mathrm{m}^{-3}$.

\subsection{Variations in Density Contours with Initial Density Difference}

Figure 5 describes the LNG density contours at $100 \mathrm{~s}$. The greater the initial density difference is, the more violent the LNG rollover will be. Therefore, the preferred method of controlling LNG rollover is shortening the initial density difference between the injected LNG and the residual LNG in the storage tank.

\subsection{Influence of the Initial Density Difference on LNG Rollover Coefficients}

According to the model of Li et al. [17], the LNG rollover coefficient is written as

$$
f=\frac{\left|\Delta \rho_{\max }-\Delta \rho\right|}{t}
$$

LNG rollover coefficients vary with the initial density difference (figure 6).

In particular, the LNG rollover coefficient dramatically changes when the initial density difference exceeds a critical density difference of $7.5 \mathrm{~kg} \cdot \mathrm{m}^{-3}$. The critical density difference $\left(\Delta \rho_{\mathrm{c}}\right)$ can be converted into the critical temperature difference $\left(\Delta T_{\mathrm{c}}\right)$ by using the following equation [17]: 


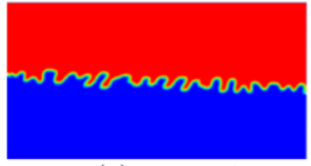

(a) $1 \mathrm{~kg} \cdot \mathrm{m}^{-3}$

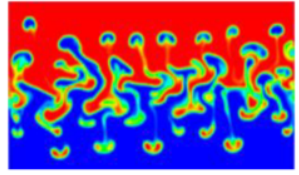

(e) $5 \mathrm{~kg} \cdot \mathrm{m}^{-3}$

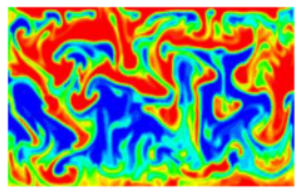

(i) $9 \mathrm{~kg} \cdot \mathrm{m}^{-3}$

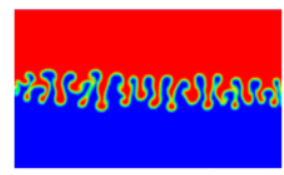

(b) $2 \mathrm{~kg} \cdot \mathrm{m}^{-3}$

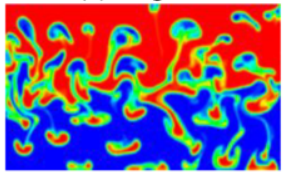

(f) $6 \mathrm{~kg} \cdot \mathrm{m}^{-3}$

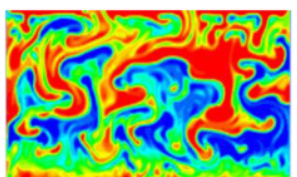

(j) $10 \mathrm{~kg} \cdot \mathrm{m}^{-3}$

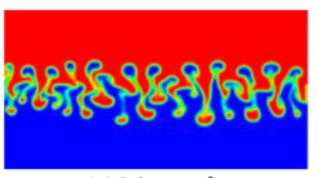

(c) $3 \mathrm{~kg} \cdot \mathrm{m}^{-3}$

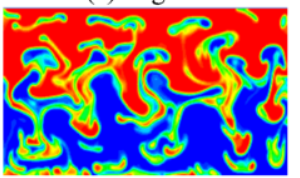

(g) $7 \mathrm{~kg} \cdot \mathrm{m}^{-3}$

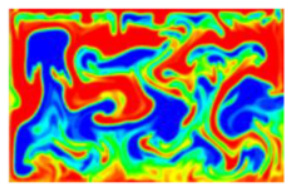

(k) $11 \mathrm{~kg} \cdot \mathrm{m}^{-3}$

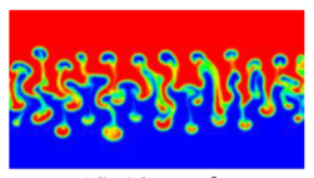

(d) $4 \mathrm{~kg} \cdot \mathrm{m}^{-3}$

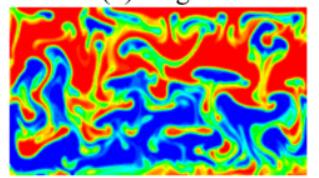

(h) $8 \mathrm{~kg} \cdot \mathrm{m}^{-3}$

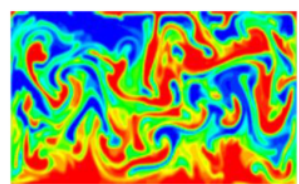

(1) $12 \mathrm{~kg} \cdot \mathrm{m}^{-3}$

Figure 5. Contours of LNG rollover for different density differences at $100 \mathrm{~s}$.

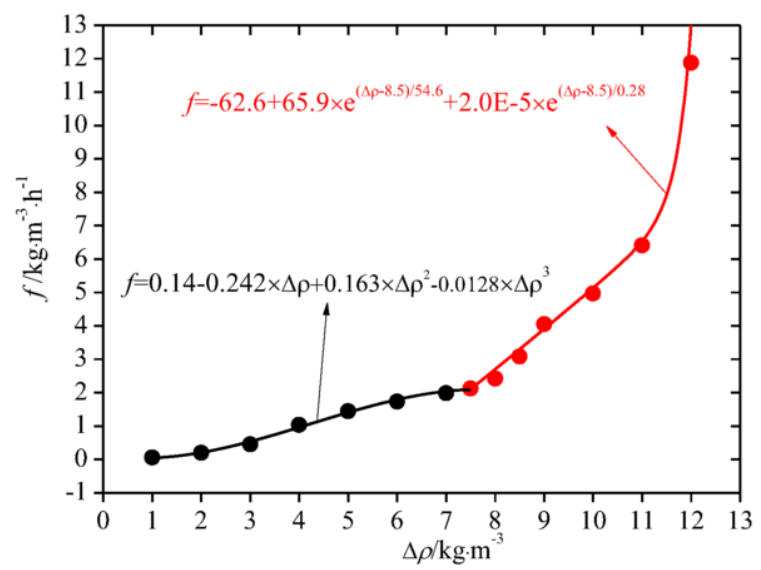

Figure 6. LNG rollover coefficients vary with initial density difference.

$$
\Delta \rho_{\mathrm{c}}=1.35 \Delta T_{\mathrm{c}}
$$

Here, the critical temperature $\Delta T_{\mathrm{c}}=5.5 \mathrm{~K}$ when $\Delta \rho_{\mathrm{c}}=7.5 \mathrm{~kg} \cdot \mathrm{m}^{-3}$.

$\mathrm{Li}$ et al. [17] also proposed a model to describe the relationship between the volume $(V)$ of LNG and $\Delta T_{\mathrm{c}}$ :

$$
\Delta T_{\mathrm{c}}=-0.855 \ln V+12.48
$$

$V$ of the present numerical LNG storage tank is $6333 \mathrm{~m}^{3}$, and its $\Delta T_{\mathrm{c}}$ is $5.0 \mathrm{~K}$. The error between the present critical density difference and the theoretical model is $10 \%$, which is within an acceptable range.

At the initial density difference less than $7.5 \mathrm{~kg} \cdot \mathrm{m}^{-3}$, the LNG rollover coefficients 
are expressed as:

$$
f=0.14-0.242 \cdot \Delta \rho+0.163 \cdot \Delta \rho^{2}-0.0128 \cdot \Delta \rho^{3}
$$

At the initial density difference larger than $7.5 \mathrm{~kg} \cdot \mathrm{m}^{-3}$, the rollover coefficients increase dramatically as:

$$
f=-62.6+65.9 \cdot \exp [(\Delta \rho-8.5) / 54.6]+2.0 \mathrm{E}-5 \cdot \exp [(\Delta \rho-8.5) / 0.28]
$$

\section{Conclusions}

A numerical method is used to simulate the rollover behavior of LNG in a storage tank. The conclusions can be summarized as follows.

(1) When the higher-density LNG is injected into the storage tank, the LNG rollover rapidly occurs. The greater the initial density difference is, the more violent the LNG rollover will be. In rollover process, the upper layer drops first, and the bottom layer drops and moves upward. Subsequently, the two layers mix gradually. Lastly, the mixed LNG achieves a steady state.

(2) The development process of LNG rollover is directly controlled by the initial density difference. A density difference of $7.5 \mathrm{~kg} \cdot \mathrm{m}^{-3}$ is proposed as the critical density difference. When the initial density difference achieves and exceeds the critical point of $7.5 \mathrm{~kg} \cdot \mathrm{m}^{-3}$, the LNG rollover coefficients increase dramatically.

(3) The rollover coefficient model consists of two parcels, i.e., a cubic relationship between rollover coefficients and the initial density difference when the density difference is less than $7.5 \mathrm{~kg} \cdot \mathrm{m}^{-3}$ and secondly, a linear relationship between the rollover coefficient and the double exponential functions when the density difference is larger than $7.5 \mathrm{~kg} \cdot \mathrm{m}^{-3}$.

\section{Acknowledgment}

The work is supported by Natural Science Foundation of Shaanxi Province of China (No. 2020JQ-772).

\section{References}

[1] Kulitsa K and Wood D A 2018 LNG rollover challenges and their mitigation on floating storage and regasification units: new perspectives in assessing rollover consequences Loss Prevent Proc. 54 352-372.

[2] Scurlock R G 2016 Stratification, Rollover and Handling of LNG, LPG and Other Cryogenic Liquid Mixtures (Berlin: Springer).

[3] Scurlock R G 2016 Factors Creating Stratification: Management of LNG Rollover in Stratification, Rollover and Handling of LNG, LPG and Other Cryogenic Liquid Mixtures (Berlin: Springer).

[4] Baker N and Creed M 1996 Stratification and rollover in liquefied natural gas storage tanks: Major hazards onshore and offshore II Process Saf. Environ. Prot. 74 25-30.

[5] Sarten J A 1972 LNG stratification and rollover Pipeline Gas 199 37-42.

[6] Tuner J S 1965 The coupled turbulent transports of salt and heat across a sharp density interface Int. J. Heat Mass Transfer 8 759-767. 
[7] Chatterjee N and Geist J M 1972 The effect of stratification on boil-off rate in LNG tanks Pipeline Gas 199 40-45.

[8] Germeles A E 1975 A model for LNG tank rollover Adv Cryog. Eng. 21 326-336.

[9] Heesatand J, Shipman C W and Meader J W 1983 A predictive model for rollover in stratified LNG tanks AICHE 29 199-207.

[10] Gursu S, Sherif S A, Veziroglu T N and Sheffield J W 1993 Analysis and optimization of thermal stratification and self-pressurization effects in liquid hydrogen storage systems-part 1: Model development Energ. Resour. 115 221-227.

[11] Shi J Q, Beduz C and Scurlock R G 1993 Numerical modelling and flow visualization of mixing of stratified layers and rollover in LNG Cryogenics 33 1116-1124.

[12] Baker N and Greed M 1995 Stratification and rollover in liquefied natural gas storage tanks Institution of Chemical Engineers Symposium Series 139 621-634.

[13] Bates S and Morrison D S 1997 Modeling the behavior of stratified liquid natural gas in storage tanks: a study of the rollover phenomenon Int. J. Heat Mass Transfer 40 1875-1884.

[14] Kiran B D, William B Z, Malcolm T T, Marcus B W and Michal W L 2011 Optimization methods for the real-time inverse problem posed by modelling of liquefied natural gas storage Chem. Eng. J. 170 44-52.

[15] Arjomandnia P, Tade M O, Pareek V and May E F 2014 Analysis of available data from liquefied natural gas rollover incidents to determine critical stability ratios AICHE $\mathbf{6 0} 362-374$.

[16] Koyama K 2007 CFD simulation on LNG storage tank to improve safety and reduce cost Systems Modeling and Simulation (New York: Springer).

[17] Li Y X, Li Z L and Wang W C 2015 Simulating on rollover phenomenon in LNG storage tanks and determination of the rollover threshold Loss Prevent Proc. 37 132-142. 